\title{
Left Cardiac Ventricular Systolic Dysfunction Evaluation
}

National Cancer Institute

\section{Source}

National Cancer Institute. Left Cardiac Ventricular Systolic Dysfunction Evaluation. NCI

Thesaurus. Code C99975.

An examination and assessment of the inability of the left ventricle to effectively pump blood to the body. (ACC) 